\title{
Covid-19-related vs Covid-19-unrelated Acute Respiratory Distress Syndrome - Key Differences
}

\author{
Harish Mallapura Maheshwarappa, Moumita Chakraborty ${ }^{1}$, Amal T.J. Joseph ${ }^{2}$, Sibiya Poonely Chacko ${ }^{3}$, Ramya B M ${ }^{4}$ \\ Consultant Intensivist, Department of Critical Care Medicine, Mazumdar Shaw Medical Centre, Narayana Health City, 'Lecturer-Respiratory Care Technology, \\ Narayana Hrudayalaya Institute of Medical Sciences, ${ }^{2}$ Respiratory Therapist, Department of Respiratory Therapy, Narayana Health City, ${ }^{3}$ Associate Consultant, \\ ${ }^{4}$ Department of Anesthesia, Mazumdar Shaw Medical Centre, Narayana Health City, Bengaluru, Karnataka, India
}

\section{Abstract}

A recent global pandemic has resulted from the outbreak of coronavirus disease (COVID-19) infection. One of the key clinical features of this infection is the presence of severe acute respiratory syndrome coronavirus 2 virus. The port of entry for COVID-19 is the lung and if the infection worsens, it progresses to acute respiratory distress syndrome (ARDS). As the pandemic continue to surge, findings from studies and case reports suggest that the ARDS caused by COVID-19 might have different characteristics than what we refer to as non-COVID-19 (Typical) ARDS. By applying the differences in clinical features between COVID-19-related ARDS and typical ARDS, clinicians may develop appropriate therapeutic protocols to treat these patients effectively. Our review article intends to elucidate these differences in clinical features based on time of onset, radiological specifications, lung mechanics, phenotypical characters, inflammatory mediator response, and nature of coagulation abnormality.

Keywords: Acute respiratory distress syndrome phenotypes, compliance, COVID-19, COVID-19-related acute respiratory distress syndrome, hypercoagulation

\section{INTRODUCTION}

In December of 2019, the officials in Wuhan China reported an outbreak of a coronavirus disease (COVID-19) that includes a clinical feature of severe acute respiratory syndrome coronavirus 2 (SARS-CoV-2). That has led to a global pandemic. ${ }^{[1]}$ On January 2020, China's scientists succeeded in the isolation of SARS-CoV-2 virus and they have identified it as the causative agent of the virus-induced pneumonia. In concordance with the WHO's definition of the infection, it has been termed as COVID-19. The transmission mode was described to as a person-to-person droplet, contact, and airborne mode. ${ }^{[2]}$ The clinical manifestations of COVID-19 involves high body temperature (pyrexia), myalgia, fatigue, and dry nonproductive cough. ${ }^{[3]}$

Hypoxemia may develop if the patient acquires severe illness within a week after the onset of the disease, that might then progress to acute respiratory distress syndrome (ARDS). ${ }^{[3]}$ "Typical" ARDS is characterized by noncardiogenic pulmonary edema, shunt-related refractory

\begin{tabular}{|l|l|}
\hline & \multicolumn{3}{|c|}{ Access this article online } \\
\hline Quick Response Code: & Website: \\
\hline & www.ijrc.in \\
\hline
\end{tabular}

hypoxemia, with diminished functional lung size that accounts for low lung compliance. ${ }^{[4]}$ The standard definition for "typical" ARDS and its etiology (direct and indirect causes) is elaborated elsewhere. ${ }^{[5]}$ Whether COVID-19-related ARDS can be defined as "Typical" ARDS or whether there is differences in its characteristics in comparison is what we aim to elucidate in this review article.

\section{Materials and Methods}

An extensive literature search on the same topic was carried

Address for correspondence: Dr. Harish Mallapura Maheshwarappa, MBBS, MD, DM (Critical Care Medicine), IDCCM, EDICM, DNB, Consultant Intensivist, Department of Critical Care Medicine, Mazumdar Shaw Medical Centre, Narayana Health City, Bommasandra, Bengaluru - 560 099, Karnataka, India. E-mail: dr.harishmm@rocketmail.com

This is an open access journal, and articles are distributed under the terms of the Creative Commons Attribution-NonCommercial-ShareAlike 4.0 License, which allows others to remix, tweak, and build upon the work non-commercially, as long as appropriate credit is given and the new creations are licensed under the identical terms.

For reprints contact: WKHLRPMedknow_reprints@wolterskluwer.com

How to cite this article: Maheshwarappa HM, Chakraborty M, Joseph AT, Chacko SP, Ramya BM. Covid-19-related vs Covid-19-unrelated acute respiratory distress syndrome - Key differences. Indian J Respir Care 2021;10:10-3.

Received: $26-09-2020$

Accepted: 07-12-2020

Revised: 07-12-2020 Published: $31-01-2021$ 
out for 3 months from April 2020 to July 2020. Google Scholar and PUBMED search engines were used to search for relevant articles, using keywords "COVID-19-related ARDS, typical ARDS, symptoms of COVId-19 ARDS, radiological findings in COVID-19 ARDS, difference in immune response between ARDS and COVID-19-related ARDS, hyper-coagulopathy in COVID-19 ARDS, phenotypes-COVID-19-related ARDS Original articles, findings from case reports and relevant review articles were included in our article. Figure 1 describes the steps used in inclusion of articles for this review.

\section{The Berlin acute respiratory distress syndrome criteria-time of onset}

According to the Berlin criteria for ARDS, the period from symptom onset to the development of ARDS is within 7 days. ${ }^{[5,6]}$ However, this timeline does not hold true for COVID-19-related ARDS. ${ }^{[7]}$ Several studies have shown contrasting findings with relation to the time of onset. A study by Wang et $a l .{ }^{[8]}$ reported the median duration from symptom onset to the development of ARDS (in 138 COVID-19-positive cases) was 8.0 days. An interesting observation was reported in a study by Zhou et al. ${ }^{[9]}$ The study involved 191 patients; the median time from symptom onset to development of ARDS was found to be 12.0 days, while the median time for the development of dyspnea was 13.0 days. Another study also reported similar observation, where the duration from the illness onset to developing ARDS was found in the range of $8-12.5$ days. $^{[10]}$

\section{Radiological specifications}

The Berlin definition for ARDS states that the "imaging criterion for ARDS is the presence of bilateral infiltrate on chest X-ray that cannot be explained by effusion, collapsed lung, or lung nodule." ${ }^{[5]}$ Studies have reported that chest $\mathrm{X}$-ray is a less sensitive modality (with a sensitivity of $69 \%$ ) in the detection of COVID-19 as compared to chest computed tomography $(\mathrm{CT}){ }^{[11]}$ Respiratory failure secondary to COVID-19 clinically presents as pneumonia, while imaging findings are contrasting as it represents atypical pneumonia X-ray chest of later stages shows a combination

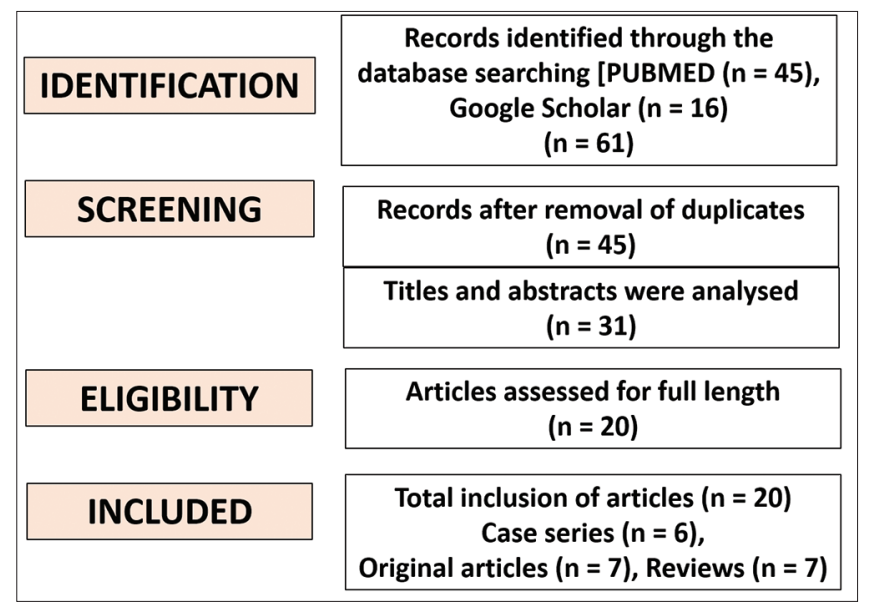

Figure 1: Flow chart to show studies included in the current review of pan lobar pattern of lung involvement along with multiple consolidation. ${ }^{[12]} \mathrm{A}$ case series report by Chung et al ${ }^{[13]}$ stated that COVID-19 chest CT consisted of peripherally distributed bilateral ground-glass appearance. Although consolidation with exudates was observed, yet it was not of the "typical" ARDS image. A study noted the unique features in COVID-19 pneumonia patients in China in comparison to viral pneumonia patients in the USA. It reported that patients with COVID-19 pneumonia showed a significantly higher opacification as well as increased vascular thickening. ${ }^{[14]}$

\section{Lung mechanics}

A case series of 16 mechanically ventilated COVID-19 patients, described a peculiar finding in patients with severe ARDS; there was severe hypoxemia despite relatively normal lung compliance. ${ }^{[15]}$ The lung compliance might be relatively normal in some COVID-19-related ARDS patients which is in contrast to our understanding of ARDS. ${ }^{[7]}$

A similar observation was also discussed by Zhou et al., ${ }^{[9]}$ in this paper. In concordance to Zhou et al.'s paper, Magro et al. ${ }^{[16]}$ also reported that in COVID-19-related ARDS, there is relatively well-preserved lung compliance despite severe hypoxemia. Hence, the respiratory failure associated with COVID-19-related ARDS is contrasting to "typical" ARDS. The paper also mentioned that rather than fibro proliferative changes, there appeared to produce thrombotic microvascular injury. A review by Preckel et al. ${ }^{[17]}$ emphasized two morphologically different "typical" ARDS phenotypes-focal nonrecruitable and nonfocal recruitable. COVID-19 pneumonia manifests as focal nonrecruitable ARDS, which can be ventilated with low driving pressures. This is in conjunction with a study by Constantin et al. ${ }^{[18]}$ who reported that in comparison to focal ARDS, diffuse ARDS presents with lower lung compliance and higher recruitability (characteristic of "typical ARDS") that responds well to high levels of positive end-expiratory pressure (PEEP) and recruitment maneuvers. Tsolaki et al. ${ }^{[19]}$ came up with unique observations in line with the above findings. In the study, PEEP level was applied according to the predefined criterion to manage ARDS. They found that when PEEP levels were de-escalated, a significant three-fold decrease in vasopressor support could maintain the hemodynamics, portraying the fact that when relatively high PEEP is applied to almost normal compliant lung, there will be an increase in pleural pressure and cause detrimental effect to hemodynamics. Unlike typical ARDS, the majority of COVID-19 lungs do not present as "baby lung" as they cannot be characterized as stiff and hence may not benefit from higher PEEP.

\section{Phenotypes}

Another literature by Gattinoni et al. ${ }^{[20]}$ has mentioned the presence of two phenotypes of COVID-19. According to this model, patients present initially with low compliance and also low recruitability. The paper has characterized this type as "L-phenotype." Another phenotype mentioned in the paper is "H-phenotype" were over time the L type might progress and 
lead to low compliance and high recruit ability. Whether there is the presence of phenotypes and whether the phenotypes if found, are in line with various models suggested in literature; depends on findings from large sample sized trials. More insights might be stated only after randomized trials are done to find if the such different phenotypes exist. The immediate result of the inflammatory process involved in ARDS include profound hypoxemia, decrease in lung compliance and increase in intrapulmonary shunting and dead space. ${ }^{[21]}$

Chiara Robba et al. ${ }^{[2]}$ in his paper, have mentioned regarding phenotypes of COVID-19 related ARDS based on the CT findings. The paper mentioned three distinct phenotypes and stated the lung recruitment strategies and modalities unique to each phenotype. According to the paper, phenotype 1 was characterized near normal compliance, but severe hypoxemia. PEEP setting might be done according to the optimal driving pressure.

Inhaled nitric oxide might be of benefit in this case, while prone positioning is considered less useful. Phenotype 2 was characterized as atelectasis and de-recruitment. High PEEP, recruitment maneuvers (RMs) and prone positioning might produce positive results in recruitment in this case. Phenotype 3 was characterized as typical chest-CT seen with moderate to severe ARDS, characterized by alveolar edema and diminished compliance. PEEP to be set based on optimal driving pressure; RMs, prone positioning, and Extracorporeal membrane oxygenation may also be considered.

\section{Inflammatory mediator response}

The pathological inflammatory mechanism in COVID-19 ARDS is explained elsewhere in literature. ${ }^{[23]}$ COVID-19 can be described as a triad of vascular dysfunction, dysregulated pattern of inflammatory response and thrombosis. Literature also focuses on the term "cytokine storm" associated with COVID-19-related ARDS. It denotes release of inflammatory mediators which is associated to hyperactive immune response. These mediators include interferons, chemokines, and tumor-necrosis factor. Cytokine storm hence implies to higher levels of released cytokines that are injurious to host cells. Interleukin (IL) - 6 is the key mediator responsible for the acute inflammatory response phase and the resulting cytokine storm. Leisman et al. ${ }^{[24]}$ in his paper, have highlighted that the reported inflammatory response observed in COVID-19 was not in line with typical ARDS. Other smaller COVID-19 studies also showed contrasting elevation levels of IL-6 associated with COVID-19-related ARDS.

\section{Coagulopathy}

The available literature on the pathogenesis of COVID-19 suggests that the main receptor for the binding of SARS-CoV-2 virus to the host cells is through the angiotensin converting-enzyme (ACE) 2 receptor. The protein expression of ACE-2 receptor is responsible for the initiation of infection and consequent phenotypic expression, that includes venous, arterial and microvascular thrombotic events. ${ }^{[25]}$ In concordance to this, Helms et al. ${ }^{[26]}$ compared patients of COVID-19 ARDS and non-COVID-19-related ARDS. It was observed that the occurrence of thromboembolic events and incidence of pulmonary embolism (PE) were seen significantly higher in COVID-19-related ARDS patients. Furthermore, coagulation parameters were higher in COVID-19-related ARDS while D-dimers values were higher in non COVID-19-related ARDS. Ranucci et al. ${ }^{[27]}$ in his study also reported coagulation analyses where it was seen that the clot strength (measured with thromboelastometry) was higher in COVID-19-related ARDS.

In a case series by Goyal et al. ${ }^{[28]}$ found that when tissue plasminogen activator was administered to patients with COVID-19, it improved oxygenation and dyspnea and supplemental oxygen could be weaned off within 7 days. Wichmann et al. ${ }^{[29]}$ in their paper reported the findings of 12 autopsies of COVID-19 patients. It showed a high incidence of PE regardless of the presence of deep venous thrombosis. The cause of death in one-third of the cases was found to be due to massive PE.

Mahjoub et al. ${ }^{[30]}$ in their paper, also mentioned similar vascular involvement in COVID-19-related ARDS.

\section{ConcLusion}

COVID-19-related ARDS might have a completely different picture than what is known regarding the "Typical ARDS." Certain major differences, such as time of onset, presence of high compliance phenotypic character, hyper coagulation, onset of hypoxemia without marked dyspnea, ${ }^{[31]}$ have lead us to question the concept of "baby lung" that is characteristic of ARDS. In addition, the literature has emphasized on how high PEEP levels that is generally used as a modality of the lung protective ventilation in ARDS may not provide similar beneficial effects in the recruit ability of the lung. To have a clear picture of whether COVID-19-related ARDS can be considered as "typical ARDS" needs randomized large scale studies with larger sample sizes. This will also help in developing protocol driven intervention modalities for combating COVID-19-related ARDS.

\section{Financial support and sponsorship}

Nil.

\section{Conflicts of interest}

There are no conflicts of interest.

\section{ReFERENCES}

1. Wu F, Zhao S, Yu B, Chen YM, Wang W, Song ZG, et al. A new coronavirus associated with human respiratory disease in China. Nature 2020;579:265-9.

2. Dreher M, Kersten A, Bickenbach J, Balfanz P, Hartmann B, Cornelissen $\mathrm{C}$, et al. The characteristics of 50 Hospitalized COVID-19 patients with and without ARDS. Dtsch Arztebl Int 2020;117:271-8.

3. Wu C, Chen X, Cai Y, Xia J, Zhou X, Xu S, et al. Risk factors associated with acute respiratory distress syndrome and death in patients with coronavirus disease 2019 pneumonia in Wuhan, China. JAMA Intern Med 2020;180:934-43.

4. Gattinoni L, Marini JJ, Pesenti A, Quintel M, Mancebo J, Brochard L. 
The baby lung became an adult. Intensive Care Med 2016;42:663-73.

5. Zulkifli A, Astrid A. Comparison of new ARDS criteria (Berlin) with Old Criteria (AECC) and its application in country with limited facilities. J Gen Emerg Med 2017;2:10.

6. ARDS Definition Task Force, Ranieri VM, Rubenfeld GD, Thompson BT, Ferguson ND, Caldwell E, et al. Acute respiratory distress syndrome: The berlin definition. JAMA 2012;307:2526-33.

7. $\mathrm{Xu} \mathrm{Li}$, Xiaochun MA. Acute respiratory failure in COVID-19: Is it "typical" ARDS? Crit Care 2020;198:24.

8. Wang D, Hu B, Hu C, Zhu F, Liu X, Zhang J, et al. Clinical characteristics of 138 hospitalized patients with 2019 novel coronavirus-infected pneumonia in Wuhan, China. JAMA 2020;323:1061-9.

9. Zhou F, Yu T, Du R, Fan G, LiuY, Liu Z, et al. Clinical course and risk factors for mortality of adult inpatients with COVID-19 in Wuhan, China: A retrospective cohort study. Lancet 2020;395:1054-62.

10. The European Society for Cardiology. ESC Guidance for the Diagnosis and Management of CV Disease during the COVID-19 Pandemic. Available from: https://www.escardio.org/Education/ COVID-19-and-Cardiology/ESCCOVID-19-Guidance. [Last accessed on 2020 Jun 10].

11. Wong HY, Lam HY, Fong AH, Leung ST, Chin TW, Lo CS, et al. Frequency and distribution of chest radiographic findings in patients positive for COVID-19. Radiology 2020;296:E72-8.

12. Fatima S, Ratnani I, Husain M, Surani S. Radiological findings in patients with COVID-19. Cureus 2020;12:e7651.

13. Chung M, Bernheim A, Mei X, Zhang N, Huang M, Zeng X, et al. CT imaging features of 2019 novel coronavirus (2019-nCoV). Radiology 2020;295:202-7.

14. Gibson PG, Qin L, Puah SR. COVID-19 acute respiratory distress syndrome (ARDS): Clinical features and differences from typical pre-COVID-19 ARDS. Med J Aust 2020;213:54-6.

15. Fan E, Beitler JR, Brochard L, Calfee CS, Ferguson ND, Slutsky AS, et al. COVID-19-associated acute respiratory distress syndrome: Is a different approach to management warranted? Lancet Respir Med 2020;8:816-21.

16. Magro C, Mulvey JJ, Berlin D, Nuovo G, Salvatore S, Harp J, et al. Complement associated microvascular injury and thrombosis in the pathogenesis of severe COVID-19 infection: A report of five cases. Transl Res 2020;220:1-3.

17. Preckel B, Schultz MJ, Vlaar AP, Hulst AH, Hermanides J, de Jong MD, et al. Update for anaesthetists on clinical features of COVID-19 patients and relevant management. J Clin Med 2020;9:1495.
18. Constantin JM, Grasso S, Chanques G, Aufort S, Futier E, Sebbane M, et al. Lung morphology predicts response to recruitment maneuver in patients with acute respiratory distress syndrome. Crit Care Med 2010;38:1108-17.

19. Tsolaki V, Siempos I, Magira E, Kokkoris S, Zakynthinos GE, Zakynthinos S. PEEP levels in COVID-19 pneumonia. Crit Care 2020;24:303.

20. Gattinoni L, Chiumello D, Caironi P, Busana M, Romitti F, Brazzi L, et al. COVID-19 pneumonia: Different respiratory treatments for different phenotypes? Intensive Care Med 2020;46:1099-102.

21. Papazian L, Aubron C, Brochard L, Chiche JD, Combes A, Dreyfuss D, et al. Formal guidelines: Management of acute respiratory distress syndrome. Ann Intensive Care 2019;9:69.

22. Robba C, Battaglini D, Ball L, Patroniti N, Loconte M, Brunetti I, et al. Distinct phenotypes require distinct respiratory management strategies in severe COVID19. Respir Physiol Neurobiol 2020;279:103455.

23. Merad M, Martin JC. Author correction: Pathological inflammation in patients with COVID-19: A key role for monocytes and macrophages. Nat Rev Immunol 2020;20:448.

24. Leisman DE, Deutschman CS, Legrand M. Facing COVID-19 in the ICU: Vascular dysfunction, thrombosis, and dysregulated inflammation. Intensive Care Med 2020;46:1105-8.

25. Becker RC. COVID-19 update: COVID-19-associated coagulopathy. J Thromb Thrombol 2020;50:54-67.

26. Helms J, Tacquard C, Severac F, Lorant LI, Ohana M, Delabranche X, et al. High risk of thrombosis in patients with severe SARS-CoV-2 infection: A multicenter prospective cohort study. Intensive Care Med 2020;46:1089-98.

27. Ranucci M, Ballotta A, Di Dedda U, Bayshnikova E, Dei Poli M, Resta M, et al. The procoagulant pattern of patients with COVID-19 acute respiratory distress syndrome. J Thromb Haemost 2020;18:1747-51.

28. Goyal A, Saigal S, Niwariya Y, Sharma J, Singh P. Successful use of tPA for thrombolysis in COVID related ARDS: A case series. J Thromb Thrombolysis 2020;2:1-4.

29. Wichmann D, Sperhake JP, Lütgehetmann M, Steurer S, Edler C, Heinemann A, et al. Autopsy findings and venous thromboembolism in patients with COVID-19. Ann Intern Med 2020; May 6: M20-2003. Published online 2020 May 6. doi: 10.7326/M20-2003.

30. Mahjoub Y, Rodenstein DO, Jounieaux V. Severe COVID-19 disease: Rather AVDS than ARDS? Crit Care 2020:24:327.

31. Archer SL, Sharp WW, Weir EK. Differentiating COVID-19 pneumonia from acute respiratory distress syndrome and high altitude pulmonary edema: Therapeutic implications. Circulation 2020;142:101-4. 